\title{
Role of the Rapid Drink Challenge Test in Esophageal Motility Disorder Diagnosis
}

\author{
Li-Chang Hsing and Kee Wook Jung* \\ Department of Gastroenterology, University of Ulsan College of Medicine, Asan Medical Center, Seoul, Korea
}

Article: Role of rapid drink challenge during esophageal high-resolution manometry in predicting outcome of peroral endoscopic myotomy in patients with achalasia

Foisy H, Pioche M, Chabrun E, et al

(J Neurogastroenterol Motil 2020;26:204-214)

Advanced esophageal manometry based on a high-resolution system expanded the understanding of esophageal physiology compared with conventional manometry. ${ }^{1,2}$ The Chicago classification is based on high resolution manometry and could enhance the diagnostic yield better than the conventional criteria. ${ }^{3}$ Diagnosis according to the Chicago classification and its protocol is based on the ten 5 -mL swallows in the supine position. ${ }^{2}$ However, with the current Chicago classification protocol, unknown or ambiguous motility findings remain.,

Provocative tests to supplement to the conventional esophageal manometry protocol have improved the diagnostic yield of the Chicago classification for esophageal motility disorders. ${ }^{4}$ Solid or semi-solid swallow, multiple rapid swallows, and the rapid drink challenge (RDC) can add to the conventional manometry protocol by supporting the current esophageal manometry criteria. ${ }^{4}$ Solid or semi-solid swallow is usually performed by instructing the patient to swallow bread or apple sauce. ${ }^{5-7}$ Multiple rapid swallows, comprising 5 swallows of 2-mL liquid with 2- or 3-second intervals, showed potential usefulness in the assessment of contractile reserve in the esophagus. ${ }^{8-10}$

The RDC test is usually performed by instructing the patient to drink $200-\mathrm{mL}$ water as fast as possible. ${ }^{11,12}$ This test can reinforce the central and peripheral deglutitive inhibitions of the esophagus. ${ }^{4}$ Therefore, it can increase suppression of esophageal body contraction and complete relaxation of the lower esophageal sphincter. ${ }^{11,12}$ It showed good potential in the assessment of esophagogastric junction function. ${ }^{11-13}$ A study showed that a cutoff integrated relaxation pressure of $>12 \mathrm{mmHg}$ indicated discrimination between achalasia and esophagogastric junction outflow obstruction without achalasia. ${ }^{11,12}$ Moreover, RDC showed good reliability in estimating esophageal stasis by comparing timed barium esophagography in patients with achalasia. ${ }^{14}$

In the paper by Foisy et $\mathrm{al},{ }^{15} \mathrm{RDC}$ showed potential usefulness in the assessment of esophageal body contractility in achalasia even after peroral endoscopic myotomy (POEM). In contrast, conventional manometry profiles of the Chicago classification between

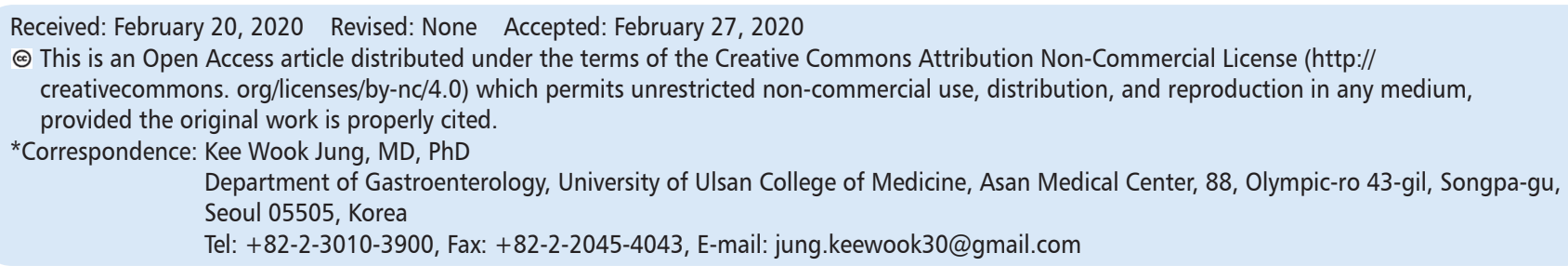


pre-and post-POEM that were measured conventionally using 10 single swallows were not associated with outcome after POEM. ${ }^{15}$ However, several limitations of the study remain, including retrospective design, and relatively short follow-up after POEM. ${ }^{15}$ Owing to the relatively small study sample, differences by procedure performers could not be determined. Nevertheless, this study showed potential ability of RDC to predict the clinical outcome of achalasia even after POEM.

Other studies reported that the use of an endoluminal functional probe (endoFLIP) with a panometry pattern might predict the outcome after POEM in achalasia or other spastic motor disorders. ${ }^{16,17}$ However, endoFLIP is relatively expensive and not widely available. RDC can be relatively easy to perform during the conventional manometry protocol, but more data based on large sample are needed to elucidate its potential role in the prediction of outcome in patients with achalasia. ${ }^{4,15}$

\section{Financial support: None.}

\section{Conflicts of interest: None.}

\section{References}

1. Pandolfino JE, Ghosh SK, Rice J, Clarke JO, Kwiatek MA, Kahrilas PJ. Classifying esophageal motility by pressure topography characteristics: a study of 400 patients and 75 controls. Am J Gastroenterol 2008;103:2737.

2. Kahrilas PJ, Bredenoord AJ, Fox M, et al. The Chicago Classification of esophageal motility disorders, v3.0. Neurogastroenterol Motil 2015;27:160-174.

3. Roman S, Gyawali CP, Xiao Y, Pandolfino JE, Kahrilas PJ. The Chicago classification of motility disorders: an update. Gastrointest Endosc Clin N Am 2014;24:545-561.

4. Carlson DA, Roman S. Esophageal provocation tests: are they useful to improve diagnostic yield of high resolution manometry? Neurogastroenterol Motil 2018;30:e13321.

5. Wong U, Person EB, Castell DO, von Rosenvinge E, Raufman JP, Xie G. Improving high-resolution impedance manometry using novel viscous and super-viscous substrates in the supine and upright positions: a pilot study. J Neurogastroenterol Motil 2018;24:570-576.
6. Blonski W, Vela M, Hila A, Castell DO. Normal values for manometry performed with swallows of viscous test material. Scand J Gastroenterol 2008;43:155-160.

7. Basseri B, Pimentel M, Shaye OA, Low K, Soffer EE, Conklin JL. Apple sauce improves detection of esophageal motor dysfunction during high-resolution manometry evaluation of dysphagia. Dig Dis Sci 2011;56:1723-1728.

8. Kushnir V, Sayuk GS, Gyawali CP. Multiple rapid swallow responses segregate achalasia subtypes on high-resolution manometry. Neurogastroenterol Motil 2012;24:1069-e1561.

9. Shaker A, Stoikes N, Drapekin J, Kushnir V, Brunt LM, Gyawali CP. Multiple rapid swallow responses during esophageal high-resolution manometry reflect esophageal body peristaltic reserve. Am J Gastroenterol 2013;108:1706-1712.

10. Min YW, Shin I, Son HJ, Rhee PL. Multiple rapid swallow maneuver enhances the clinical utility of high-resolution manometry in patients showing ineffective esophageal motility. Medicine (Baltimore) 2015;94:e1669.

11. Marin I, Serra J. Patterns of esophageal pressure responses to a rapid drink challenge test in patients with esophageal motility disorders. Neurogastroenterol Motil 2016;28:543-553.

12. Ang D, Hollenstein M, Misselwitz B, et al. Rapid drink challenge in high-resolution manometry: an adjunctive test for detection of esophageal motility disorders. Neurogastroenterol Motil 2017;29:e12902.

13. Biasutto D, Mion F, Garros A, Roman S. Rapid drink challenge test during esophageal high resolution manometry in patients with esophago-gastric junction outflow obstruction. Neurogastroenterol Motil 2018;30:e13293.

14. Ponds FA, Oors JM, Smout AJPM, Bredenoord AJ. Rapid drinking challenge during high-resolution manometry is complementary to timed barium esophagogram for diagnosis and follow-up of achalasia. Neurogastroenterol Motil 2018;30:e13404.

15. Foisy H, Pioche M, Chabrun E, et al. Role of rapid drink challenge during esophageal high-resolution manometry in predicting outcome of peroral endoscopic myotomy in patients with achalasia. J Neurogastroenterol Motil 2020;26:204-214.

16. Carlson DA, Lin Z, Kahrilas PJ, et al. The functional lumen imaging probe detects esophageal contractility not observed with manometry in patients with achalasia. Gastroenterology 2015;149:1742-1751.

17. Carlson DA, Kahrilas PJ, Lin Z, et al. Evaluation of esophageal motility utilizing the functional lumen imaging probe. Am J Gastroenterol 2016;111:1726-1735. 